\title{
Activators of Peroxisome Proliferator-activated Receptor $\gamma$ Have Depot-specific Effects on Human Preadipocyte Differentiation
}

\author{
Maria Adams, ${ }^{\star}$ Carl T. Montague, ${ }^{\star}$ Johannes B. Prins, ${ }^{\star}$ Julie C. Holder, ${ }^{\ddagger}$ Stephen A. Smith, ${ }^{\ddagger}$ Louise Sanders, ${ }^{\star}$ Jan E. Digby, ${ }^{\star}$ \\ Ciaran P. Sewter, ${ }^{\star}$ Mitchell A. Lazar, ${ }^{\S}$ V. Krishna K. Chatterjee, ${ }^{\star}$ and Stephen O’Rahilly* \\ *Department of Medicine, Addenbrookes Hospital, University of Cambridge, Cambridge CB2 2QQ, United Kingdom; ${ }^{\ddagger}$ Department of \\ Vascular Biology, SmithKline Beecham Pharmaceuticals, The Pinnacles, Harlow, Essex CM19 5AD, United Kingdom; and ${ }^{\S}$ Division of \\ Endocrinology, Diabetes, and Metabolism, Department of Medicine, Department of Genetics, and Department of Pharmacology, \\ University of Pennsylvania School of Medicine, Philadelphia, Pennsylvania 19104
}

\begin{abstract}
Activation of peroxisome proliferator-activated receptor (PPAR) $\gamma$, a nuclear receptor highly expressed in adipocytes, induces the differentiation of murine preadipocyte cell lines. Recently, thiazolidinediones (TZDs), a novel class of insulin-sensitizing compounds effective in the treatment of non-insulin-dependent diabetes mellitus (NIDDM) have been shown to bind to PPAR $\gamma$ with high affinity. We have examined the effects of these compounds on the differentiation of human preadipocytes derived from subcutaneous (SC) and omental (Om) fat. Assessed by lipid accumulation, glycerol 3-phosphate dehydrogenase activity, and mRNA levels, subcultured preadipocytes isolated from either SC or Om depots did not differentiate in defined serum-free medium. Addition of TZDs (BRL49653 or troglitazone) or 15$\operatorname{deoxy} \Delta^{12,14}$ prostaglandin $\mathbf{J}_{2}$ (a natural PPAR $\gamma$ ligand) enhanced markedly the differentiation of preadipocytes from SC sites, assessed by all three criteria. The rank order of potency of these agents in inducing differentiation matched their ability to activate transcription via human PPAR $\gamma$. In contrast, preadipocytes from Om sites in the same individuals were refractory to TZDs, although PPAR $\gamma$ was expressed at similar levels in both depots. The mechanism of this depot-specific TZD response is unknown. However, given the association between Om adiposity and NIDDM, the site-specific responsiveness of human preadipocytes to TZDs may be involved in the beneficial effects of these compounds on in vivo insulin sensitivity. (J. Clin. Invest. 1997. 100:3149-3153.) Key words: thiazolidinediones • human adipocyte differentiation $\cdot$ peroxisome proliferator-activated receptor $\bullet$ insulin resistance
\end{abstract}

M. Adams, C.T. Montague, and J.B. Prins contributed equally to the work presented.

Address correspondence to Dr. Stephen O'Rahilly, Department of Medicine, Level 5, Addenbrookes Hospital, University of Cambridge, Cambridge CB2 2QQ, UK. Phone: 44-1223-336855; FAX: 441223-330160; E-mail: sorahill@hgmp.mrc.ac.uk

Received for publication 13 March 1997 and accepted in revised form 7 October 1997.

J. Clin. Invest.

(C) The American Society for Clinical Investigation, Inc. 0021-9738/97/12/3149/05 \$2.00

Volume 100, Number 12, December 1997, 3149-3153

http://www.jci.org

\section{Introduction}

Thiazolidinediones (TZDs) ${ }^{1}$ are orally active agents that enhance insulin sensitivity in vivo. Although their precise mechanism of action is unknown, they are of proven efficacy in the treatment of non-insulin-dependent diabetes mellitus (1) and amelioration of insulin resistance associated with polycystic ovary syndrome (2). Based on studies in murine cell lines, it has been recognized recently that the compounds are ligands for the peroxisome proliferator-activated receptor (PPAR) $\gamma$, a nuclear hormone receptor that is highly expressed in adipose tissue $(3,4)$. The two isoforms of PPAR $\gamma,-\gamma 1$ and $-\gamma 2$, share sequence homology with the related receptors PPAR $\alpha$ and PPAR $\delta$, although each receptor subtype differs in tissue distribution. As the antihyperglycemic potential of TZDs is proportional to their potency in activation of PPAR $\gamma(5,6)$, this raises the possibility that the insulin-sensitizing effects of TZDs may be mediated through activation of this receptor. However, TZDs, acting through PPAR $\gamma$, are also potent promoters of murine preadipocyte differentiation. As obesity is the most common cause of human insulin resistance, this presents the intriguing paradox that TZDs, although adipogenic in vitro, are effective insulin sensitizing agents in vivo.

In humans, adipose tissue is dynamic, with the lifelong potential for hyperplasia through preadipocyte replication and differentiation. Preadipocytes are precursor cells found in the stromovascular compartment that are committed to the adipocyte lineage. Differentiation involves a complex regulatory pathway controlled by the coordinate expression of specific regulatory genes and several transcription factors, including ADD1 (7), C/EBP $\alpha,-\beta$, and $-\gamma(8)$, and CHOP (9) as well as PPAR $\gamma$ have been implicated in this process. The tissue specificity of PPAR $\gamma$ expression, combined with its ability to modulate the transcription of adipocyte-specific genes, suggests that PPAR $\gamma$ in particular plays an important role in preadipocyte differentiation. This suggestion is strengthened by the rapid and sustained increase in the expression of PPAR $\gamma 2$ mRNA which accompanies differentiation of cultured murine preadipocyte cell lines (10), the ability of PPAR $\gamma$ ligands to induce differentiation in these cell lines (11-13), and the induction of adipocyte-specific genes and accumulation of lipid observed in fibroblasts and myoblasts after retrovirally mediated overex-

1. Abbreviations used in this paper: DAP, dihydroxyacetone phosphate; $15 \mathrm{dPGJ}_{2}$, 15-deoxy $\Delta^{12,14}$ prostaglandin $\mathrm{J}_{2}$; G3PDH, glycerol 3-phosphate dehydrogenase; h, human; Om, omental; PPAR, peroxisome proliferator-activated receptor; RT-PCR, reverse-transcriptase PCR; SC, subcutaneous; TZD, thiazolidinedione. 
pression of PPAR $\gamma 2(10,14)$. To date, investigation of the role of PPAR $\gamma$ in preadipocyte differentiation has focused primarily on murine preadipocyte cell lines. However, although these provide useful model systems, the role of PPAR $\gamma$ stimulation in human preadipocyte differentiation has not been addressed.

Given the key role that PPAR $\gamma$ plays in murine preadipocyte differentiation, and in view of the potential clinical applications of the TZD class of insulin sensitizers, we have investigated the ability of these compounds and 15 -deoxy $\Delta^{12,14}$ prostaglandin $\mathrm{J}_{2}$ $\left(15 \mathrm{dPGJ}_{2}\right.$, a putative endogenous ligand for PPAR $\gamma$ ) to activate a human PPAR $\gamma$ reporter construct in vitro. In parallel, we have investigated the expression of PPAR $\gamma$ isoforms in human tissues and examined the ability of TZDs and $15 \mathrm{dPGJ}_{2}$ to promote differentiation of human preadipocytes. As the accumulation of omental $(\mathrm{Om})$ fat is much more strongly associated with insulin resistance than is subcutaneous (SC) obesity, we have also sought to explore whether there are any potentially relevant adipose depot-specific effects of TZDs.

\section{Methods}

Plasmid constructs. GAL4-PPAR $\gamma$ contains residues $175-477$ of the human (h) PPAR $\gamma$ hormone binding domain, PCR-amplified from human adipocyte RNA and cloned into the EcoRI site of pSG424. GAL4-PPAR $\delta$ contains residues 138-440 of hPPAR $\delta$. UAS-TKLUC luciferase reporter, containing two copies of the GAL4 17-mer binding site, and Bos- $\beta$-GAL have been described previously (15).

Transfection studies. 1BR cells (16), grown on 24-well plates in DME plus $1 \%$ penicillin/streptomycin/fungizone (GIBCO BRL, Gaithersburg, MD), were transfected with $10 \mathrm{ng}$ of receptor expression vector, $500 \mathrm{ng}$ of UAS-TKLUC reporter plasmid, and $100 \mathrm{ng}$ of Bos- $\beta$-GAL internal control by 4 -h exposure to $\mathrm{CaPO}_{4}$. After an additional 40-h incubation with either drug or the appropriate vehicle, cells were lysed, luciferase values were normalized to $\beta$-galactosidase activity, and fold-activation was calculated as described previously (15).

Patient recruitment and adipose biopsy. Om and abdominal SC adipose tissue biopsies were obtained from patients undergoing elective open-abdominal surgery. All patients fasted for at least $6 \mathrm{~h}$ preoperatively, and all underwent general anesthesia. None of the patients had diabetes or severe systemic illness or had had any recent weight change. None were taking medications known to affect adipose tissue mass or metabolism. Cambridge Local Research Ethics Committee approval was obtained, and all patients gave their informed consent.

Preadipocyte culture and differentiation. Biopsies were transported to the laboratory in normal saline (transport time $5 \mathrm{~min}$ ), and preadipocytes and adipocytes were obtained by collagenase digestion and centrifugation using standard protocols. Preadipocytes were cultured in DME/Ham's F12 medium supplemented with $10 \%$ FBS and antibiotics. Cultures were passaged two to three times and grown to confluence. At confluence, the medium was changed to a serum-free hormonally modified differentiating medium (17), with addition of compound or vehicle as appropriate.

Glycerol 3-phosphate dehydrogenase (G3PDH) activity. Preadipocytes cultured in six-well plates were washed in PBS (pH 7.4), harvested into $1 \mathrm{ml}$ of ice-cold Tris ( $\mathrm{pH} 7.5$ ) containing $1 \mathrm{mM}$ EDTA and $500 \mu \mathrm{M}$ DL-DTT, and transferred to a prechilled microtube. Cells were disrupted by sonication and then centrifuged at 12,000 $\mathrm{g}$ for 15 $\min$ at $2^{\circ} \mathrm{C}$. The supernatant was then assayed for G3PDH activity in a final concentration of $100 \mathrm{mM}$ triethanolamine- $\mathrm{HCl}(\mathrm{pH} 7.5), 2.5$ $\mathrm{mM}$ EDTA, $0.12 \mathrm{mM}$ NADH, $50 \mu \mathrm{M}$ DL-DTT, and $0.2 \mathrm{mM}$ dihydroxyacetone phosphate (DAP) in a 1 -ml volume $(250 \mu \mathrm{l}$ superna$\operatorname{tant} / 740 \mu l$ assay mixture minus substrate/10 $\mu \mathrm{l} \mathrm{DAP})$. The reaction was initiated by the addition of DAP, and the $\mathrm{A}_{340}$ was followed in a spectrophotometer (Shimadzu Scientific Instruments, Inc., Columbia, $\mathrm{MD})$ at $30^{\circ} \mathrm{C}$ over a $1-\mathrm{cm}$ light path for 6 min to obtain an initial reaction rate. Each of three culture wells was assayed in duplicate with a suitable reagent blank containing distilled water instead of the enzyme's substrate. An aliquot of the supernatant was assayed for protein using a standard method (18). The results were expressed as milliunits per milligram of supernatant protein, $1 \mathrm{mU}$ of enzyme activity being the amount catalyzing the oxidation of $1 \mathrm{nmol} \mathrm{NADH} / \mathrm{min}$.

Reverse-transcriptase (RT) PCR. After isolation of adipocytes, total RNA was extracted immediately using a guanidinium thiocyanate-phenol technique (TRIzol reagent; Sigma Chemical Co., St. Louis, MO). G3PDH gene expression was quantified by quantitative RT-PCR as described previously (19).

Western blotting. Preadipocytes and adipocytes were isolated from adipose biopsies and lysed in RIPA buffer (1\% NP-40, 1\% sodium deoxycholate, $0.1 \%$ SDS, $0.15 \mathrm{M} \mathrm{NaCl}, 0.01 \mathrm{M} \mathrm{NaPO}_{4}, \mathrm{pH} 7.2$, and $2 \mathrm{mM}$ EDTA containing $1 \mathrm{mM}$ PMSF, $2 \mu \mathrm{M}$ leupeptin, and $5 \mu \mathrm{g} /$ $\mathrm{ml}$ aprotinin). Cell extracts (40 $\mu \mathrm{g}$ protein) were subjected to SDSPAGE fractionation, blotted onto nitrocellulose membrane, and probed with primary antibody. Immunoreactivity was visualized using an enhanced chemiluminescence kit (ECL; Amersham Corp., Arlington Heights, IL).

\section{Results}

Activation of $h P P A R \gamma$ by $T Z D$ s and $15 d P G J_{2}$. The selectivity of the TZDs BRL49653 and troglitazone, and $15 \mathrm{dPGJ}_{2}$ for hPPAR subtypes was characterized using chimeric receptors containing the GAL4 DNA-binding domain linked to the hormone-binding domain of either hPPAR $\gamma$ (GAL4-PPAR $\gamma$ ) or

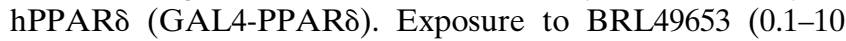
$\mu \mathrm{M})$ caused a dose-related increase in transcription after cotransfection with GAL4-PPAR $\gamma$ and UAS-TKLUC reporter plasmids (Fig. $1 a$ ). Similar effects were observed with troglitazone $(1-10 \mu \mathrm{M})$, although this compound was less potent. However, SB209501, a structurally-related compound that is inactive in studies of murine preadipocyte differentiation, was unable to activate transcription in cells transfected with GAL4-PPAR $\gamma$ (data not shown). Both BRL49653 (Fig. 1

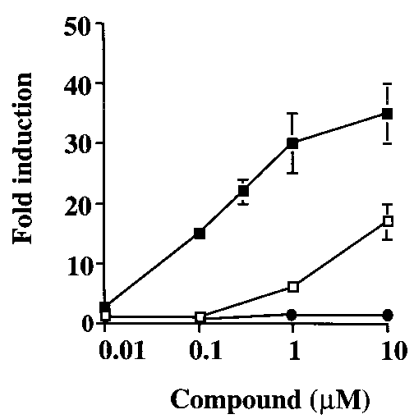

b

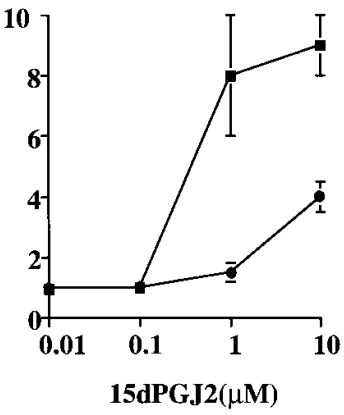

Figure 1. TZDs and $15 \mathrm{dPGJ}_{2}$ activate transcription through $\mathrm{hPPAR} \gamma$

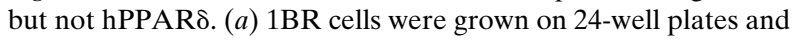
transfected with $10 \mathrm{ng}$ of GAL4-PPAR $\gamma$ (squares) or GAL4-PPAR $\delta$ (circles) expression vector, $500 \mathrm{ng}$ of UAS-TKLUC, and $100 \mathrm{ng}$ of Bos- $\beta$-GAL. Induction of normalized luciferase activity was determined after a 40-h incubation with increasing concentrations of BRL49653 (filled symbols) or troglitazone (open symbols). Results are the mean \pm SEM of four separate transfections, each done in triplicate wells. (b) As above, except the cells were cultured in increasing concentrations of $15 \mathrm{dPGJ}_{2}$. 

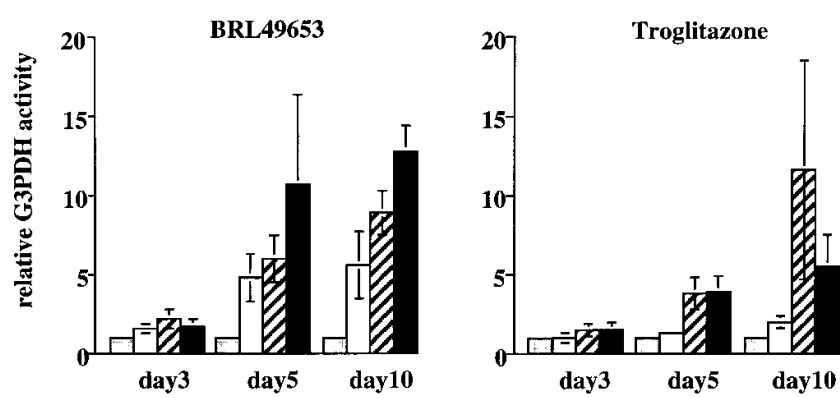

Figure 2. TZDs increase G3PDH activity in SC preadipocytes. Cells from the stromovascular fraction of SC adipose tissue biopsies were grown to confluence on 3-cm plates. Differentiation medium was supplemented with $(a)$ BRL49653 or $(b)$ troglitazone $\left(10^{-8} \mathrm{M}\right.$, white bars; $10^{-7} \mathrm{M}$, hatched bars; $10^{-6} \mathrm{M}$, black bars; vehicle control, gray bars). Cells were harvested 3, 5, or $10 \mathrm{~d}$ later, and G3PDH activity in cell lysates was determined. Results are the mean \pm SEM of values obtained from cells cultured from six different individuals.

a) and troglitazone (data not shown) failed to induce reporter gene activity in the presence of GAL4-PPAR $\delta$. Differences in transcriptional activation by PPAR subtypes were also apparent after exposure to $15 \mathrm{dPGJ}_{2}$; in the presence of the GAL4-PPAR $\gamma$ chimera, this prostanoid activated transcription maximally at a concentration of $1 \mu \mathrm{M}$, whereas with GAL4-PPAR $\delta$, a higher concentration $(10 \mu \mathrm{M})$ was able to induce only relatively low levels of transcription (Fig. $1 b$ ).

$T Z D$ s and $15 d P G J_{2}$ promote differentiation of human preadipocytes in culture. To investigate the role of hPPAR $\gamma$ in the differentiation of human preadipocytes, cells from the preadipocyte-enriched adipose tissue stromovascular fraction obtained from SC abdominal adipose tissue were harvested and subcultured two to three times. Individual preadipocyte cultures were then grown to confluence in serum-containing medium before exposure to differentiation medium containing insulin, T3, and hydrocortisone (termed day 0). After $10 \mathrm{~d}$ of culture under these conditions, lipid accumulation was apparent in $<5 \%$ of cells. In contrast, after supplementation of the differentiation medium with $0.1 \mu \mathrm{M}$ BRL49653, lipid droplets were observed in $15-20 \%$ of the SC-derived cells. Similar results were observed after culture in medium supplemented with $1 \mu \mathrm{M} 15 \mathrm{dPGJ}_{2}$. More quantitative assessment of differentiation was achieved by assay of G3PDH mRNA levels and enzyme activity. TZDs enhanced markedly G3PDH activity in the SC-derived cells (Fig. 2). Thus, treatment of SC preadipocytes with BRL49653 caused an increase in activity that was both dose- and time-related; enzyme activity was increased significantly by each concentration at day 5 , and by $\sim 15$-fold after $10 \mathrm{~d}$ of exposure to $10 \mu \mathrm{M}$ BRL49653. This observation was consistent among individuals (samples from six patients studied) and highly significant $(P<0.001$ vs. treatment with vehicle only, by Student's $t$ test). Exposure to troglitazone also increased G3PDH activity in preadipocytes from the same individuals. However, this was apparent only after $10 \mathrm{~d}$ of culture. Furthermore, the magnitude of induction was less than that observed with BRL49653 (fivefold increase at day 10), which accords with the lesser potency of this TZD in activating hPPAR $\gamma$.

Depot-specific differences in TZD activity. In parallel studies, we observed marked differences in the ability of TZDs to promote the differentiation of preadipocytes derived from $\mathrm{Om}$ compared with SC tissue from the same individuals. In these studies of paired samples from the same individuals, Om preadipocytes were much less responsive to BRL49653, assessed by observation of lipid accumulation within cells (Fig. 3). G3PDH mRNA levels and enzyme activity were used as a more quantitative measure of adipocyte differentiation. When assessed by quantitative RT-PCR, G3PDH mRNA levels were consistently higher in SC compared with Om cells after TZD treatment (data not shown). Differential sensitivity to TZDs a

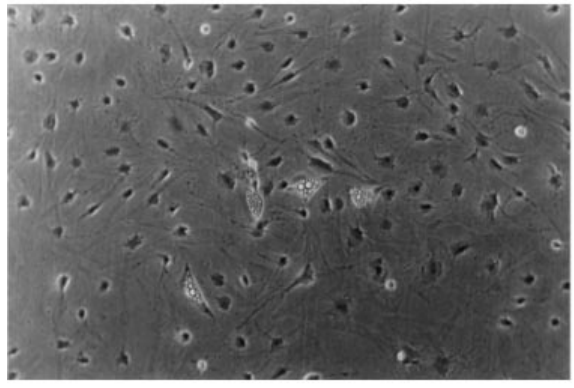

c

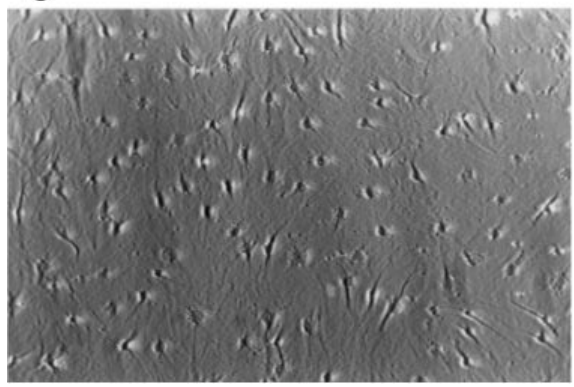

b

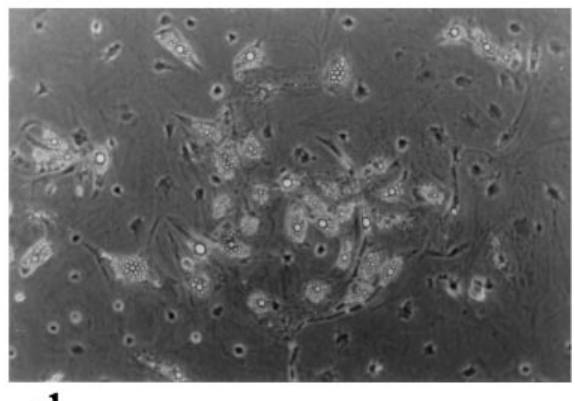

d

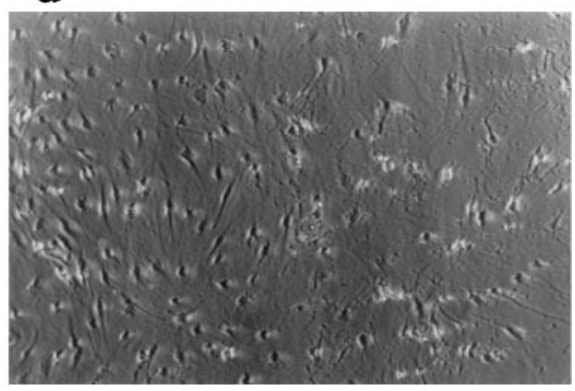

Figure 3. TZD treatment promotes lipid accumulation in SC but not Om preadipocytes. Cells from the stromovascular fraction of adipose tissue biopsies were grown to confluence in 3 - $\mathrm{cm}$ plates before differentiation was induced. Phase-contrast photomicrographs of cells isolated from SC (upper panels) and Om (lower panels) depots after $17 \mathrm{~d}$ of culture in differentiation medium alone ( $a$ and $c$ ) or plus $10 \mu \mathrm{M}$ BRL49653 ( $b$ and $d)$. 


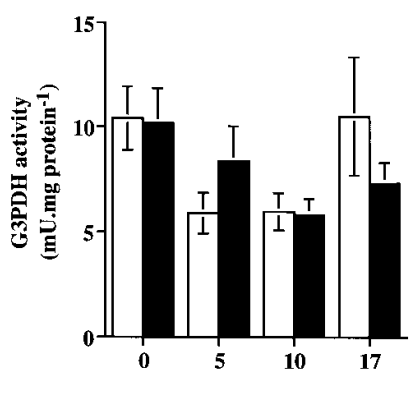

days post-differentiation

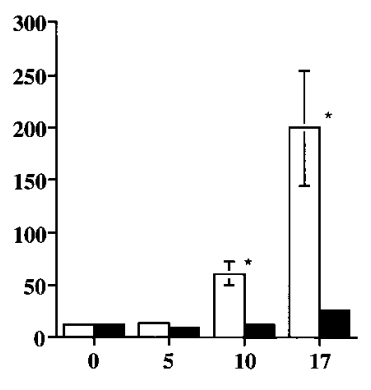

days post-differentiation

Figure 4. TZD treatment promotes G3PDH expression and activity in $\mathrm{SC}$ but not Om preadipocytes. Cells from the stromovascular fraction of SC and Om adipose tissue biopsies from the same individuals were grown to confluence before differentiation was induced in control medium (left) or in medium supplemented with $10 \mu \mathrm{M}$

BRL49653 (right), and G3PDH activity in cell extracts was measured 5,10 , and $17 \mathrm{~d}$ later. The results are the mean \pm SEM of paired Om (black bars) and SC (white bars) preadipocyte cultures from 18 individuals. *Significant difference between G3PDH activity in BRL49653 and control-treated SC cells $(P<0.001$, Student's $t$ test $)$.

was also apparent after measurement of G3PDH enzyme activity (Fig. 4). In these studies of paired samples from 18 individuals, G3PDH activity was not altered in cells from either depot grown in control differentiation medium, supporting previous reports of the refractoriness of subcultured human preadipocytes to differentiate (17). However, after treatment with BRL49653, G3PDH activity increased significantly in SC but not Om preadipocytes at days 10 and 17 of treatment $(P<$ 0.001 , Student's $t$ test), indicating a marked difference in TZD responsiveness between preadipocytes from the two depots.

$P P A R \gamma$ expression in human preadipocytes and adipocytes. The divergent effects of TZDs in inducing the differentiation of human SC but not Om preadipocytes at concentrations that activate hPPAR $\gamma$ led us to investigate hPPAR $\gamma$ expression in the two depots. Similar receptor levels were detected in immunoblots of freshly isolated preadipocytes and mature adipocytes in the same individuals using an antibody that recognizes both PPAR $\gamma 1$ and $-\gamma 2$ isoforms (Fig. 5). Furthermore, there were no consistent differences in levels of PPAR $\gamma 1$ expression between samples from SC and Om adipose tissue from the same individuals. In each case, the most prominent band comigrated with in vitro-translated hPPAR $\gamma 1$, whereas the band corresponding to the size predicted of hPPAR 2 was much less intense and not apparent in all individuals. In contrast, extracts from differentiated 3T3 L1 cells, which were used as a positive control, displayed two prominent bands corresponding to PPAR $\gamma 1$ and $-\gamma 2$ isoforms, respectively. PPAR $\gamma 1$ expression was also apparent in human skeletal muscle (Fig. 5).

\section{Discussion}

In this study, we have demonstrated that the TZDs BRL49653 and troglitazone stimulate the transcriptional activity of hPPAR $\gamma$. BRL49653 is a more potent activator of hPPAR $\gamma$ than troglitazone, whereas SB209501, a structurally related compound, does not stimulate receptor activity. This reflects

the potency of these agents in promoting the differentiation of human SC preadipocytes. Furthermore, adipogenesis also occurs after culture with the prostanoid $15 \mathrm{dPGJ}_{2}$ at concentrations that activate PPAR $\gamma$-mediated gene transcription selectively. Thus, the rank order of potencies of TZDs in activating PPAR $\gamma$ and promoting human SC preadipocyte differentiation reflects the potency of these compounds in promoting insulin sensitivity in vivo (5). This supports the suggestion that the latter two effects of TZDs are mediated via this receptor.

In contrast to preadipocytes from SC adipose tissue, Om preadipocytes are refractory to the differentiation-promoting effects of these compounds, indicating an intrinsic difference in susceptibility to PPAR $\gamma$ agonists between SC and Om preadipocytes from the same individual. This depot-specific difference cannot be explained on the basis of PPAR $\gamma$ expression, which was equal in both depots, and is somewhat unexpected, given that retroviral expression of PPAR $\gamma$ in murine fibroblasts is sufficient to initiate the adipocyte-differentiation pathway (10). We have shown recently that phosphorylation within the amino-terminus of PPAR $\gamma$ inhibits its liganddependent transcriptional activity $(20,21)$. However, as the mobility of PPAR $\gamma$ from either depot, determined by immunoblotting, is identical, we consider it unlikely that differences in the phosphorylation state of the receptor accounts for the divergent depot-responsiveness. It is well-recognized that there are differences in gene expression between SC and Om adipose depots which lead to differences in the expression of, for example, glucocorticoid receptors (22) and leptin (19). Similarly, insulin action appears to differ between the two sites (23). This latter observation might be of particular significance, given the synergy observed between PPAR $\gamma$ and insulin in the transactivation of adipocyte-specific gene expression in 3T3 L1 adipocytes (24). Alternatively, as PPAR $\gamma$-dependent activation of transcription is mediated through PPAR-retinoid $\mathrm{X}$ receptor heterodimers $(25,26)$, it is possible that differences

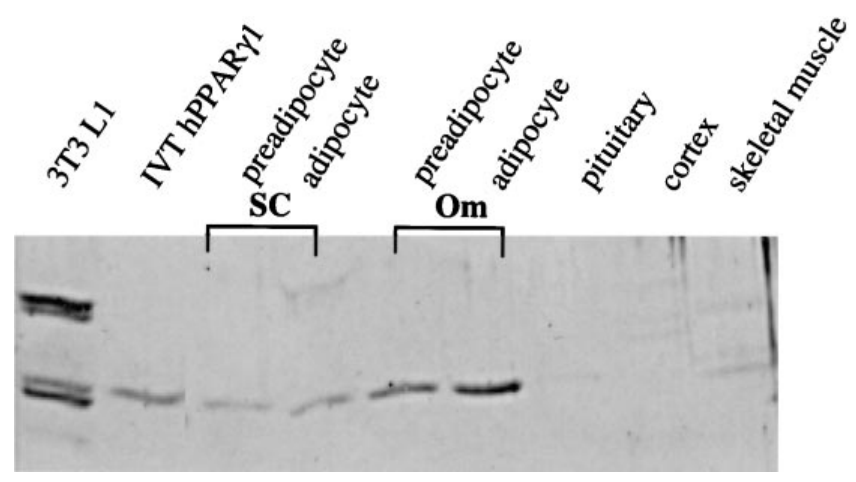

Figure 5. Human adipocytes derived from both SC and Om depots express PPAR $\gamma$. Protein extracts ( $40 \mu \mathrm{g}$ total protein) were fractionated by SDS-PAGE and blotted, and PPAR $\gamma$ expression was determined using a specific PPAR $\gamma$ antibody that recognizes both PPAR $\gamma 1$ and $-\gamma 2$ isoforms. The relative positions of PPAR $\gamma 1$ and $-\gamma 2$ isoforms, apparent in 3T3 L1 adipocyte extracts and in vitro-translated $(I V T)$ hPPAR $\gamma 1$, are included as controls. PPAR $\gamma 1$ is expressed to similar levels in freshly isolated preadipocytes and adipocytes, with no consistant difference in PPAR $\gamma 1$ protein levels observed between Om and SC depots from the same individual. PPAR $\gamma 1$ expression is also apparent in human skeletal muscle but not pituitary or cerebral cortex. 
in retinoid $\mathrm{X}$ receptor expression exist between the two sites. Finally, following studies of other nuclear hormone receptors, it is likely that transcriptional activity of PPAR $\gamma$ is mediated by complex interactions with corepressor and coactivator proteins. Site-specific differences in cofactor expression might influence receptor action.

The in vivo effects of TZDs reported to date indicate potent insulin-sensitizing effects in both rats and humans. Although in humans there appears to be little increase in weight during treatment, increases in fat mass have been reported in rodents $(27,28)$. There are several potential explanations for this disparity. First, we show that PPAR $\gamma$ is also expressed in human skeletal and cardiac muscle, suggesting that its human distribution may be less restricted than in murine tissues $(10$, 29). Thus, in humans, TZDs might exert significant effects on skeletal muscle (a major insulin-responsive organ) as well as adipose tissue. Second, as suggested by our data, TZDs may have a depot-specific adipogenic effect. In humans, insulin resistance is strongly correlated with measures of visceral (including Om) adiposity, and considerable published evidence exists supporting intrinsic differences between SC and Om adipose cells. Interventions that alter adipose distribution away from the visceral depot could potentially improve insulin sensitivity. Thus, given the dynamic nature of adipose tissue, if TZDs were to favor the accumulation of excess energy stores in the SC rather than Om adipose depot, this alone could contribute to an insulin-sensitizing effect. Future clinical studies of TZDs that examine effects on fat distribution will be of considerable interest. Finally, it is possible that TZDs have an as yet uncharacterized effect on appetite or metabolic rate in vivo that might act to counteract the adipogenic effects of insulin sensitization and promotion of preadipocyte differentiation observed in vitro.

\section{Acknowledgments}

We thank Edmund Andersen for technical assistance.

M. Adams, J. Prins, V.K.K. Chatterjee, and S. O'Rahilly are supported by the Wellcome Trust, C. Montague by the Medical Research Council, and C. Sewter by the British Diabetic Association. M.A. Lazar is supported by grant DK-49780 from the National Institutes of Health.

\section{References}

1. Nolan, J.J., B. Ludvik, P. Beerdsen, M. Joyce, and J. Olefsky. 1994. Improvement in glucose tolerance and insulin resistance in subjects treated with troglitazone. N. Engl. J. Med. 333:1386-1390.

2. Dunaif, A., D. Scott, D. Finegood, B. Quintana, and R. Whitcomb. 1996. The insulin-sensitizing agent troglitazone improves metabolic and reproductive abnormalities in polycystic ovary syndrome. J. Clin. Endocrinol. Metab. 81: 3299-3306.

3. Tontonoz, P., E. Hu, R.A. Graves, A.I. Budavari, and B.M. Spiegelman. 1994. mPPAR $\gamma 2$ : tissue-specific regulator of an adipocyte enhancer. Genes Dev. 8:1224-1234.

4. Chawla, A., E.J. Schwarz, D.D. Dimaculangan, and M.A. Lazar. 1994 Peroxisome proliferator-activated receptor (PPAR) gamma: adipose-predominant expression and induction early in adipocyte differentiation. Endocrinology. 135:798-800.

5. Berger, J., P. Bailey, C. Biswas, C.A. Cullinan, T.W. Doebber, N.S. Hayes, R. Saperstein, R.G. Smith, and M.D. Leibowitz. 1996. Thiazolidinediones produce a conformational change in peroxisomal-proliferator activated receptor- $\gamma$ : binding and activation correlate with antidiabetic actions in $d b / d b$ mice. Endocrinology. 137:4189-4195.

6. Wilson, T.H., J.E. Cobb, D.J. Dowan, R.W. Wiethe, I.D. Correa, S.R. Prakash, K.D. Beck, L.B. Moore, S.A. Kliewer, and J.M. Lehman. 1996. The structure-activity relationship between PPAR $\gamma$ agonism and the antihyperglycemic activity of thiazolidinediones. J. Med. Chem. 39:665-668.

7. Kim, J.B., and B.M. Spiegelman. 1996. ADD1/SREBP1 promotes adipocyte differentiation and gene expression linked to fatty acid metabolism. Genes Dev. 10:1096-1107.

8. Cao, Z., R.M. Umek, and S.L. McKnight. 1991. Regulated expression of three C/EBP isoforms during conversion of 3T3-L1 cells. Genes Dev. 5:15381552.

9. Wang, X.Z., and D. Ron. 1996. Stress-induced phosphorylation and activation of the transcription factor CHOP (GADD153) by p38 MAP kinase. Science. 272:1347-1349.

10. Tontonoz, P., E. Hu, and B.M. Spiegelman. 1994. Stimulation of adipogenesis in fibroblasts by PPAR $\gamma 2$, a lipid-activated transcription factor. Cell. 79: 1147-1156.

11. Kliewer, S.A., J.M. Lenhard, T.M. Willson, I. Patel, D.C. Morris, and J.M. Lehmann. 1995. A prostaglandin $\mathbf{J}_{2}$ metabolite binds peroxisome proliferator-activated receptor $\gamma$ and promotes adipocyte differentiation. Cell. 8:813819.

12. Yu, K., W. Bayona, C.B. Kallen, H.P. Harding, C.P. Ravera, G. McMahon, M. Brown, and M.A. Lazar. 1995. Differential activation of peroxisome proliferator-activated receptors by eicosanoids. J. Biol. Chem. 270:2397523983.

13. Forman, B.M., P. Tontonoz, J. Chen, R.P. Brun, B.M. Spiegelman, and R.M. Evans. 1995. 15-deoxy- $\Delta^{12,14}$-prostaglandin $\mathrm{J}_{2}$ is a ligand for the adipocyte determination factor PPAR $\gamma$. Cell. 83:803-812.

14. Hu, E., P. Tontonoz, and B.M. Spiegelman. 1995. Transdifferentiation of myoblasts by the adipogenic transcription factors PPAR $\gamma$ and $\mathrm{C} / \mathrm{EBP} \alpha$. Proc. Natl. Acad. Sci. USA. 92:9856-9860.

15. Tone, Y., T.M. Collingwood, M. Adams, and V.K.K. Chatterjee. 1994 Functional analysis of a transactivation domain in the thyroid hormone $\beta$ receptor. J. Biol. Chem. 269:31157-31161.

16. Mayne, L.V., A. Priestley, M.R. James, and J.F. Burke. 1986. Efficient immortalization and morphological transformation of human fibroblasts by transfection with SV40 DNA linked to a dominant marker. Exp. Cell Res. 162: 530-538.

17. Hauner, H., G. Entenmann, M. Wabitsch, D. Gaillard, G. Ailhaud, R. Negrel, and E.R. Pfeiffer. 1989. Promoting effect of glucocorticoids on the differentiation of human adipocyte precursor cells cultured in a chemically defined medium. J. Clin. Invest. 84:1663-1670.

18. Peterson, G.L. 1997. A simplification of the protein assay method of Lowry et al. which is generally more applicable. Anal. Biochem. 83:346-356.

19. Montague, C.T., J.B. Prins, L. Sanders, J.E. Digby, and S. O'Rahilly. 1997. Depot- and sex-specific differences in regional fat distribution. Diabetes. 46:342-347.

20. Adams, M., M.J. Reginato, D. Shao, M.A. Lazar, and V.K.K. Chatterjee. 1997. Transcriptional activation by peroxisome proliferator-activated receptor $\gamma$ is inhibited by phosphorylation at a consensus mitogen-activated protein kinase site. J. Biol. Chem. 272:5128-5132.

21. Hu, E., J.B. Kim, P. Sarraf, and B.M. Spiegelman. 1996. Inhibition of adipogenesis through MAP kinase-mediated phosphorylation of PPAR $\gamma$. Science. 274:2100-2103.

22. Bronnegard, M., P. Arner, L. Hellstrom, G. Akner, and J.A. Gustafsson. 1990. Glucocorticoid receptor messenger ribonucleic acid in different regions of human adipose tissue. Endocrinology. 127:1689-1696.

23. Arner, P. 1995. Differences in lipolysis between human subcutaneous and omental adipose tissue. Ann. Med. 27:435-438.

24. Zhang, B., J. Berger, G. Zhou, A. Elbrecht, S. Biswas, S. White-Carrington, D. Szalkowski, and D.E. Moller. 1996. Insulin- and mitogen-activated protein kinase-mediated phosphorylation and activation of peroxisome proliferator-activated receptor $\gamma$. J. Biol. Chem. 271:31771-31774.

25. Kliewer, S.A., K. Umesomo, D.J. Noonan, R.A. Heyman, and R.M Evans. 1992. Convergence of 9-cis retinoic acid and peroxisome proliferator signalling pathways through heterodimer formation of their receptors. Nature. 358:771-774.

26. Keller, H., C. Dreyer, J. Medin, A. Mahfoudi, K. Ozato, and W. Wahli 1993. Fatty acids and retinoids control lipid metabolism through activation of peroxisome proliferator-activated receptor-retinoid X receptor heterodimers. Proc. Natl. Acad. Sci. USA. 90:2160-2164.

27. De Vos, P., A.M. Lefebvre, S.G. Miller, M. Guerre-Millo, K. Wong, R. Saladin, L.G. Hamann, B. Staels, M.R. Briggs, and J. Auwerx. 1996. Thiazolidinediones repress $o b$ gene expression in rodents via activation of peroxisome proliferator-activated receptor gamma. J. Clin. Invest. 98:1004-1009.

28. Zhang, B., M.P. Graziano, T.W. Doebber, M.D. Leibowitz, S. WhiteCarrington, D.M. Szalkowski, P.J. Hey, M. Wu, C.A. Cullinan, P. Bailey, et al 1996. Down-regulation of the expression of the obese gene by an antidiabetic thiazolidinedione in Zucker diabetic fatty rats and $\mathrm{db} / \mathrm{db}$ mice. J. Biol. Chem. 271:9455-9459.

29. Vidal-Puig, A., M. Jimenez-Linan, B.B. Lowell, A. Hamann, E. Hu, B. Spiegelman, J.S. Flier, and D.E. Moller. 1996. Regulation of PPAR $\gamma$ gene expression by nutrition and obesity in rodents. J. Clin. Invest. 97:2553-2561. 